\title{
Medical nutrition therapy for a patient presenting with a chylothorax
}

Kotze V, $\mathrm{RD}(\mathrm{SA})$, Lecturer, Department of Human Nutrition, University of Pretoria, Pretoria Van Schalkwyk N, RD(SA), Dietitian, Themba Hospital, Mpumalanga Correspondence to: Vanessa Kotze, e-mail: vanessa.kotze@up.ac.za Keywords: medical nutrition therapy, chylothorax

\section{Introduction}

A chylothorax can be defined as a leakage of chylous fluid from an abnormal or damaged thoracic duct or a main branch thereof, after an injury or obstruction in the pleural cavity. Management of a chylothorax includes surgical and conservative medical treatment that includes medical nutrition therapy. However, there is no clear evidence yet as to whether enteral nutrition or parenteral nutrition is the preferred nutrition support option for medical nutrition therapy.

\section{Case report}

Mr J, a 34-year-old man presented at the emergency care unit of the hospital with a stab wound to the neck above the fifth thoracic vertebra. The patient had no other known diseases or allergies, and had a previous hospital admission because of an assault. He was responsive and cooperative, but had difficulty talking because of the trauma. He reported that he drank occasionally at social events and exercised regularly.

The patient complained of chest discomfort and shortness of breath. He subsequently underwent a chest X-ray and a computed tomography angiogram, which confirmed a pleural effusion on the left side of the chest. An intercostal drain was inserted to drain the pleural fluid which appeared milky.

\section{Diagnosis}

The patient was diagnosed with a chylothorax due to a penetrating trauma to the neck.

\section{Anthropometry}

On admission, he weighed $55 \mathrm{~kg}$ and had a body mass index (BMI) of $17.3 \mathrm{~kg} / \mathrm{m}^{2}$, from which the patient was classified as underweight. ${ }^{1}$ His mid-upper-arm circumference (MUAC) and triceps skinfold were measured, from which his arm muscle area and arm fat area were determined. The patient presented with poor muscle and fat stores, as evident from his MUAC of $22.5 \mathrm{~cm}$, which was below the fifth percentile according to the National Health and Nutrition Examination Survey percentile tables. ${ }^{2,3} \mathrm{His}$ arm muscle area also fell below the fifth percentile, and his arm fat area was between the fifth and the tenth percentile. ${ }^{4}$ The patient's ideal weight was determined at a BMI of $20 \mathrm{~kg} / \mathrm{m}^{2}$ to be $63 \mathrm{~kg}$.

\section{Biochemistry}

The initial biochemistry values obtained for the patient are shown in Table I. The observed hyponatraemia and hypochloraemia most probably resulted from the increased sodium losses from the chyle leak and is characteristic in a diagnosis of chylothorax. ${ }^{5-7}$ Serum creatinine levels reflect muscle mass as it is mostly derived from the breakdown of endogenous sources, and less affected by catabolic states than urea levels. Thus, the decreased creatinine levels reflect low muscle mass in this patient which corresponded with the poor muscle stores observed using the anthropometric indicators. Urea, on the other hand, is derived from either dietary protein sources or endogenous protein sources and its formation influenced by protein intake, increased catabolism (either due to starvation or an acute phase response), as well as the absorption of protein from the blood in the gastrointestinal lumen. Although a decreased urea level can

Table I: The patient's biochemical values

\begin{tabular}{|l|c|c|}
\hline $\begin{array}{l}\text { Urea and } \\
\text { electrolytes }\end{array}$ & Normal values & $\begin{array}{c}\text { Initial patient biochemical } \\
\text { values }\end{array}$ \\
\hline $\mathrm{Na}$ & $135-145 \mathrm{mmol} / \mathrm{l}$ & $129 \mathrm{mmol} / \mathrm{l}$ \\
\hline $\mathrm{K}$ & $3.3-5.2 \mathrm{mmol} / \mathrm{l}$ & $3.5 \mathrm{mmol} / \mathrm{l}$ \\
\hline $\mathrm{Cl}$ & $99-113 \mathrm{mmol} / \mathrm{l}$ & $95 \mathrm{mmol} / \mathrm{l}$ \\
\hline $\mathrm{CO}_{2}$ & $19-29 \mathrm{mmol} / \mathrm{l}$ & $25 \mathrm{mmol} / \mathrm{l}$ \\
\hline Urea & $2.6-8 \mathrm{mmol} / \mathrm{l}$ & $1.9 \mathrm{mmol} / \mathrm{l}$ \\
\hline $\mathrm{Creat}$ & $60-100 \mathrm{mmol} / \mathrm{l}$ & $54 \mathrm{mmol} / \mathrm{l}$ \\
\hline $\mathrm{CRP}$ & $0-10 \mathrm{mg} / \mathrm{l}$ & $45 \mathrm{mg} / \mathrm{l}$ \\
\hline $\mathrm{Hb}$ & $12.1-16.3 \mathrm{~g} / \mathrm{dL}$ & $10.2 \mathrm{~g} / \mathrm{dl}$
\end{tabular}

$\mathrm{Hb}$ : haemoglobin, $\mathrm{Cl}$ chloride, $\mathrm{CO}_{2}$ : carbon dioxide, Creat: creatinine, CRP: C-reactive protein, $\mathrm{K}$ : potassium, Na: sodium 
reflect a low protein intake, the most common cause of decreased urea levels in hospitals is overenthusiastic intravenous infusion of maintenance fluid. ${ }^{8}$ There was also evidence of an ongoing acute phase response, as observed from the elevated C-reactive protein levels, the latter being a non-specific acute phase protein with a short half-life of 5-7 hours. ${ }^{7}$

\section{Clinical}

The patient appeared wasted, with unremarkable vital signs. His intercostal drainage was $360 \mathrm{ml}$ over a 24-hour period.

The patient was prescribed Clexane $^{\circledR}$, Fragmin $^{\circledR}$, Omnopon $^{\circledR}$ and Panado ${ }^{\circledR}$

\section{Dietary}

The patient was kept nil per os and Ringer's lactate infused intravenously at $100 \mathrm{ml} /$ hour. Total parenteral nutrition (TPN) was requested since there was concern that enteral nutrition could exacerbate the chyle leak, even though the intercostal drainage was only $360 \mathrm{ml}$.

The European Society for Parenteral and Enteral Nutrition guidelines on parenteral nutrition (surgery) were used to determine the patient's requirements. These guidelines recommend $25-30 \mathrm{kcal} / \mathrm{kg}$ ideal body weight per day for energy, and $1.2-1.5 \mathrm{~g} / \mathrm{kg}$ per day, or $20 \%$ of total energy intake for protein. A glucose to fat ratio of 50:50 up to $70: 30$ of the non-protein energy is recommended. ${ }^{9}$

The patient's energy needs were calculated as $25 \mathrm{kcal} / \mathrm{kg}$ ideal body weight/day non-protein energy, and his protein needs as $1.8 \mathrm{~g} / \mathrm{kg}$ body weight/day. This resulted in $113 \mathrm{~g}$ protein per day, contributing $20 \%$ to total energy. His carbohydrate needs were calculated at $70 \%$, and fat at $30 \%$, of the non-protein energy. His fluid requirement was calculated at $40 \mathrm{ml} / \mathrm{kg} / \mathrm{day}$, not accounting for drain losses. The patient was prescribed Intravenous Therapeutic Nutrition (ITN) ${ }^{\circledR}$ 5003A from the commercial sector.

Table II: Energy and macronutrient composition of total parenteral nutrition prescription (Intravenous Therapeutic Nutrition ${ }^{\circledR} 5003 A$ )

\begin{tabular}{|l|c|c|}
\hline Nutrient & Content per $\mathbf{2} 620 \mathrm{ml}$ & Dietary prescription \\
\hline Energy & $1740 \mathrm{kcal}$ NPE & $1575 \mathrm{kcal}$ (NPE) \\
\hline Nitrogen & $19.2 \mathrm{~g}$ & $18 \mathrm{~g}(113 \mathrm{~g}$ protein $)$ \\
\hline Carbohydrate & $300 \mathrm{~g}$ & $275 \mathrm{~g}(70 \% \mathrm{NPE})$ \\
\hline Fat & $50 \mathrm{~g}$ & $52.5 \mathrm{~g}(30 \% \mathrm{NPE})$ \\
\hline
\end{tabular}

NPE: non-protein energy

\section{Nutritional management}

On day 1 , the patient was started on $\operatorname{ITN}^{\circledR} 5003 \mathrm{~A}$ at $109 \mathrm{ml} /$ hour. His intercostal drainage amounted to $550 \mathrm{ml}$ for the day.

On day 2, the ICD draining was $1000 \mathrm{~mL} / 24 \mathrm{hrs}$. The TPN was subsequently continued at the maximum calculated rate of $109 \mathrm{~mL} / \mathrm{hr}$ as well as for the following two days (day 3 and 4 post admission). The ITN ${ }^{\circledR} 5003 \mathrm{~A}$ was continued at $109 \mathrm{ml} /$ hour. No intercostal drainage was recorded on either day, but a repeat chest X-ray was performed on day 4 . It was decided to initiate oral feeds and 2 (two) tins (500mL) of a semi-elemental product were prescribed. The product is rich in medium chain triglycerides (MCTs) with seventy percent $(70 \%)$ of the fat content consisting of MCTs.

Simultaneously, the flow rate of the ITN $^{\circledR} 5003 \mathrm{~A}$ was decreased to $70 \mathrm{ml} /$ hour. This treatment was continued the following day (day 5) as no intercostal drainage had been recorded at that point of the patient's daily clinical assessment.

On day 6, the intercostal drainage was recorded as $150 \mathrm{ml}$, the TPN discontinued, and the patient prescribed a low-fat diet which he tolerated well.

\section{Literature}

A chylothorax can be defined as a leakage of chylous fluid from an abnormal or damaged thoracic duct or main branch thereof, after an injury or obstruction in the pleural cavity. ${ }^{5}$ It can also result from a cervical or thoracic node biopsy, resections (such as lung and pancreatic), other surgical procedures (such as oesophagectomy and neck dissection), as well as penetrating trauma, as was the case with this patient. ${ }^{5}$

The symptoms of a chylothorax are typically that of any pleural effusion, such as dyspnoea, coughing, chest discomfort and/or tachycardia, but the severity of the symptoms depends on the size of the chylothorax. ${ }^{5,10}$ An injury above the level of the fifth thoracic vertebra usually produces left-sided chylothorax and injuries below that level, right-sided chylothorax. ${ }^{10}$

Chyle consists of lymph from interstitial fluid and emulsified fat from intestinal lacteals and is collected and transported by the thoracic duct into the circulation. ${ }^{5,10}$ The thoracic duct usually originates from the cisterna Chyli which receives the fatty chyle from the intestinal lacteals and then transport the intestinal chyle containing digestive fat (mostly in the form of triglycerides) to the systemic venous system and lymphatics of the body. ${ }^{10}$ The lymph is derived from the gastro-intestinal tract as well as the liver and contains nutrients, lymphocytes, immunoglobulins and enzymes. ${ }^{10}$

The flow of chyle through the thoracic duct varies from $1 \mathrm{ml} /$ minute to more than $200 \mathrm{ml} /$ minute, with a total of $2-4$ I passing through it per day. The volume of chyle varies, depending on diet, intestinal absorption and degree of physical activity. ${ }^{10}$ Any activity that increases blood flow will increase chyle flow, including exercise, as well as any activities that will cause increased intra-abdominal pressure, such as coughing, for example. ${ }^{6}$ The milky appearance of the chyle is because almost all of the chyle originates from the

Table III: The nutritional composition of chyle $e^{6,10}$

\begin{tabular}{|l|c|}
\hline Component & Concentration (per $\mathbf{1 0 0} \mathbf{~ m l})$ \\
\hline Energy & $20 \mathrm{kcal}(\mathbf{8 4 \mathrm { kJ } )}$ \\
\hline Total fat & $0.4-3 \mathrm{~g}$ \\
\hline Total cholesterol & $1.68-5.69 \mathrm{mmol} / \mathrm{l}$ \\
\hline Total protein & $2.21-6 \mathrm{~g}$ \\
\hline Albumin & $1.2-4.1 \mathrm{~g}$ \\
\hline Sugar & $48-200 \mathrm{~g}$ \\
\hline Electrolytes & Similar to plasma \\
\hline
\end{tabular}


intestinal lacteal system. Approximately $70 \%$ of all dietary fat passes through this system. The fat component of chyle consists of the end products of fat digestion, namely chylomicrons, triglycerides, cholesterol and fat-soluble vitamins, but fatty acids with less than 10 carbons bypass this system, and are absorbed directly into the portal system. Chyle contains half the amount of protein as plasma, but is higher in albumin than plasma (Table III). 5, 10

The diagnosis of a chyle leak in post-traumatic pleural effusions is not well defined and the proposed methods vary from a chest $\mathrm{x}$-ray or computed tomography (CT) of the thorax to assessing the drained pleural fluid with respect to volume, composition and colour.

When assessing the volume of drained pleural fluid, there is no consensus on what amount of chyle drainage warrants treatment or not. It is proposed that in the case of an oesophagectomy, drainage of more than $500 \mathrm{ml}$ is indicative of a chyle leak. When determining the colour of the pleural fluid drainage, a change in colour after ingestion of a high-fat meal, or cessation of enteral feeding, should be sought specifically. After consumption of a high-fat food, such as cream, the pleural fluid can appear milky white or whitish in the presence of a chyle leak, but this can be misleading since in approximately half of cases with a chyle leak, the drainage can be reddish, yellow or serous. ${ }^{6,10}$ In some cases, methylene blue is added to the high-fat product, and if a chyle leak is present, the drained fluid will appear bluish-green. However, this practice might not be helpful in the case of a post-traumatic chylothorax since discoloration of pleural fluid can also occur in oesophageal perforation. ${ }^{10}$ Alternatively, tube feeds can be withheld for a time, and if the pleural fluid becomes clear, the presence of a chyle leak can be assumed. ${ }^{5}$

When determining the composition of the pleural drainage, an assessment should be made as to the presence of either chylomicron, triglyceride or lymphocyte count. The presence of chylomicrons aids in a definitive diagnosis with a composition of more than $4 \%$ chylomicrons being diagnostic of a chyle leak whilst it can be assumed that a value under $4 \%$ is a portion of the fat breakdown during the normal healing process. Testing for the presence of chylomicrons can be carried out with Sudan ${ }^{\circledR}$ III stain or lipoprotein analysis of the pleural fluid itself, but unfortunately, this is not always available at medical centres. In such instances, the presence of triglyceride levels of more than $1.24 \mathrm{mmol} / \mathrm{l}$ can then be used to diagnose chylothorax, while a level below $0.56 \mathrm{mmol} / \mathrm{l}$ rules out such a diagnosis. If the level is between $0.56 \mathrm{mmol} / \mathrm{l}$ and 1.24 $\mathrm{mmol} / \mathrm{l}$, a test should be conducted for the presence of chylomicrons to confirm the diagnosis. ${ }^{6}$ Alternatively, an elevated lymphocyte count of more than $50 \%$ the normal reference value is diagnostic of chylothorax. ${ }^{5,10}$

Some of the complications associated with a diagnosis of chylothorax include malnutrition, a compromised cell-mediated immune response and fat-soluble vitamin deficiencies, with possible symptoms of hypovolaemia, electrolyte disrturbances, hypoalbuminaemia, lymphopaenia and infection. Observed electrolyte abnormalities include metabolic acidosis, hypocalcaemia and hyponatraemia, as was observed in this patient. ${ }^{5,6,10}$ The cause of the complications that can develop relates to the composition of the chyle. For instance, the fat-soluble vitamin deficiencies that may occur in these patients relate to the loss of lipids in the chylous fluid. A large proportion of total body protein is transported in chylous fluid. Therefore, a chronic chyle leak results in protein loss, which, in turn, can result in fluid shifts and increased metabolic demand. Severe malnutrition, together with weight loss and muscle wasting, can occur in chronic chyle leak cases. A patient's nutritional status will continue to deteriorate, or poor nutrititonal status will persist, unless definitive therapeutic measures are instituted to stop the leakage of chyle into the pleural space. In this case, the patient presented with a low urea and creatinine level, which was most probably as a result of increased protein losses. It should also be borne in mind that together with the loss of protein, there is also depletion of $\mathrm{T}$ cell lymphocytes and immunoglobulins. This diminished cellmediated immunity results in a compromised immune response and a predisposition to infections and increased risk of sepsis. Infections due to the chylothorax itself are very uncommon since chyle is naturally bacteriostatic. $5,6,10$

The management of chylothorax includes both medical (including medical nutrition therapy) management and surgical management. Once the patient is haemodynamically stable, a choice can be made on the specific therapy to be followed in accordance with the size of the chylothorax and the clinician's preference. ${ }^{10}$ The medical management of a chyle leak is based on the theory that decreasing chyle flow allows for spontaneous closure of the chyle leak. ${ }^{5}$

The initial step in management of a large chylothorax that often results in respiratory distress entails therapeutic thoracentesis, the removal of fluid from the space between the lining of the outside of the lungs (pleura) and the wall of the chest. ${ }^{5}$ The preferred method for this procedure is the insertion of an intercostal drain. During excessive drainage, patients are generally kept nil per os (npo) or prescribed a diet rich in MCTs since these fatty acids are absorped directly into the portal systrem. This approach resolving about $50 \%$ of congenital and traumatic chylothoraxis. ${ }^{10} \mathrm{An}$ important adjuvant in the medical management of chylothorax is the use of octreotide, a synthetic somatostatin analogue, to reduce intestinal chyle production by reducing triglyceride absorption, and in this way, reducing the chyle leak. ${ }^{10}$ TPN is prescribed as part of the management of chronic chylothorax when there is a rapid loss of nutrients via the chyle. The most noticeable of these nutrients are protein, fat, fat-soluble vitamins and electrolytes, such as sodium, which was evident in this case. Therefore, medical treatment includes adequate drainage of the chest or other body cavities, bed rest and nutrition modification, including parenteral nutrition and the avoidance of fat. ${ }^{5,6}$

If conservative management is unsuccessful in the spontaneous closure of the fistula, surgical intervention may be necessary, especially in cases of a high-output fistula, defined as a daily chyle leak in excess of $1.5 \mathrm{l} /$ per day (some sources advocate one litre per day as a cut-off value), if the chyle drainage is more than one litre/day for five consecutive days, or if the leak does not close spontaneously after 2-3 weeks of conservative management. 6,10 The associated mortality is reported to decrease from $50 \%$ to $10 \%$ with active surgical intervention. ${ }^{10}$ Unfortunately, aggressive intervention involving reoperation can considerably increase morbidity and mortality, but if left untreated, the mortality rate of chylothorax is generally high. 
In summary, the goals of medical nutrition therapy (a "fat-free" or low-fat diet supplemented with MCT oil and fat-free oral supplements, enteral feeds containing a high percentage of MCTs, or the use of parenteral nutrition) are to decrease the production of chyle, replace fluid and electrolytes, and maintain and/or replete nutrition status. ${ }^{5,6}$ There is universal agreement that the nutritional status of the patient with a chylothorax worsens early after obtaining the pleural effusion, and that nutritional status should be stabilised with aggressive nutrition support. ${ }^{10}$

Although the primary focus of the nutrition support focus on the fat content of the diet, it has been shown that peristalsis and enteral intake, even ingesting water, can increase the lymph flow by $20 \%$. The literature on the application of either enteral or parenteral nutrition, as part of the management of chylothorax is scarce, and based on small observational trials, small retrospective trials and case reports. Some of these studies suggest the use of enteral feeding with MCTs as management of chylothorax, while others advocate the use of TPN to resolve a chyle leak. In addition, parenteral nutrition has been reported to be associated with decreased duration of conservative therapy, an increased fistula closure rate and an improved nutrition response, when compared with the administration of enteral nutrition. In this regard, some studies suggest the successful application of enteral feeds containing MCTs to manage chyle leaks as this approach does not increase chyle flow, or delay healing of the chylous fistula or the development of complications. ${ }^{10}$

\section{Conclusion}

Nutrition support is of the utmost importance in the management of a patient who presents with a chylothorax to prevent the development of complications, such as malnutrition. However, guidelines for evidence-based medical nutrition therapy are lacking with regard to the optimal route, nutrient mix and duration of nutrition support needed to manage a chyle leak.

\section{References}

1. World Health Organization. Global database on body mass index. WHO [homepage on the Internet]. 2013. C2013. Available from: http://apps.who.int/bmi/index. jsp?introPage=intro_3.html

2. McDowell MA, Fryar CD, Ogden CL, Flegal KM. Anthropometric reference data for children and adults: United States 2003-2006. Hyattsville: National Center for Health Statistics; 2011

3. Lee RD, Nieman DC. Nutritional assessment. $5^{\text {th }}$ ed. Boston: McGraw Hill; 2010 .

4. Hammond KA. Dietary and clinical assessment. In: Mahan LK, Escott-Stump S, editors. Krause's food and the nutrition care process. $11^{\text {th }}$ ed. London: WB Saunders, 2004; $p$ 407-435.

5. Nair SK, Petko M, Hayward MP. Aetiology and management of chylothorax in adults. Eur J Cardiothorac Surg. 2007;32(2):362-369.

6. McCray S, Parrish CR. Nutritional management of chyle leaks: an update. Pract Gastroenterol. 2011;94:12-32.

7. Mahan LK, Escott-Stump S, Raymond JL. Appendix 30. In: Mahan LK, Escott-Stump S, editors. Krause's food and the nutrition care process. $13^{\text {th }}$ ed. London: WB Saunders; 2012.

8. Mayne PD. Clinical chemistry in diagnosis and treatment. $6^{\text {th }}$ ed. London: Hodder Education Publishers; 1994.

9. Braga $M$, Ljunqvist 0 , Soeters $P$, et al. ESPEN guidelines on parenteral nutrition: surgery. Clin Nutr. 2009;28(4):378-386.

10. Smoke A, DeLegge MH. Chyle leaks: consensus on management? Nutr Clin Prac. 2007;23(5):529-532. 